\title{
Rhabdomyosarcomas Do Not Contain Mutations in the DNA Binding Domains of Myogenic Transcription Factors
}

\author{
Geetha Anand, * David N. Shapiro," Paul S. Dickman, ${ }^{\star}$ and Edward V. Prochownik 5 \\ Departments of ${ }^{*}$ Pediatrics and ${ }^{\ddagger}$ Pathology, Children's Hospital of Pittsburgh, Pittsburgh, Pennsylvania 15213; $\$$ Department of \\ Molecular Genetics and Biochemistry, University of Pittsburgh Medical Center, Pittsburgh, Pennsylvania 15261; \\ and "Department of Hematology, St. Jude Children's Research Hospital, Memphis, Tennessee 38101
}

\begin{abstract}
Skeletal myogenesis is regulated by a group of transcription factors (MyoD, myogenin, myf5, and myf6) that are "basic helix-loop-helix" proteins that bind to the promoters of muscle-specific genes and promote their expression. We have previously shown that after a mutation of $\mathrm{Leu}_{122}$ to Arg the DNA binding basic domain of $\mathrm{MyoD}$ confers c-myc-like functional characteristics to the protein. In this study we used singlestrand conformation polymorphism analysis to determine whether such mutations occur naturally in rhabdomyosarcomas. We have found that the basic domains of all the myogenic factors remain unaltered in rhabdomyosarcomas. Selection against such mutations may be the result of functional redundancy of these myogenic transcription factors. (J. Clin. Invest. 1994. 93:5-9.) Key words: myogenic proteins $\bullet$ myoD • SSCP • c-myc $\cdot$ muscle differentiation
\end{abstract}

\section{Introduction}

MyoD, myogenin, myf5, and myf6 are a group of muscle-specific, "basic helix-loop-helix" (bHLH) ${ }^{1}$ transcription factors that regulate skeletal myogenesis $(1-3)$. These proteins bind to the promoters of many muscle-specific genes at sites containing the canonical "E-box" sequence CANNTG. After binding, other domains within these myogenic factors activate transcription of the adjacent gene (4-7). Although some differences have been noted in the various properties of these factors and in their expression during embryogenesis ( 8-10), each one by itself is fully capable of inducing myogenic differentiation when expressed ectopically in nonmyogenic cells such as fibroblasts (11). This suggests that MyoD, myogenin, myf5, and myf6 are components of a redundant cellular mechanism for ensuring the proper timing and progression of skeletal muscle morphogenesis. This concept has gained support from recent experiments demonstrating that skeletal muscle development

Address correspondence to Dr. Edward V. Prochownik, Division of Hematology/Oncology, Children's Hospital of Pittsburgh, 3705 Fifth Avenue at DeSoto, Pittsburgh, PA 15213.

Received for publication 5 April 1993 and in revised form 6 August 1993.

1. Abbreviations used in this paper: bHLH, basic helix-loop-helix; SSCP, single-strand conformation polymorphism.

J. Clin. Invest.

(c) The American Society for Clinical Investigation, Inc. $0021-9738 / 94 / 01 / 0005 / 05 \$ 2.00$

Volume 93, January 1994, 5-9 in mice lacking functional copies of $\mathrm{MyoD}$ or myf5 proceeds relatively normally $(12,13)$.

DNA binding by the myogenic bHLH proteins requires that they first dimerize. However, such DNA binding by homodimers, while specific, is relatively weak (14). Binding is significantly enhanced by heterodimeric association with the ubiquitously expressed products of the E2A gene product (E12 and E47) and, indeed, the active transcriptional complexes in myogenic cells appear to consist of such heterodimers (14). In the case of MyoD, for example, each component of the heterodimer is thought to contribute a DNA half-site recognition specificity such that the optimal binding site (CACCTG) is a composite of the preferred binding sites of the individual components in homodimeric form (15).

myc family proteins are also members of the bHLH family and bind the E-box motif CACGTG in association with the recently described protein $\max (16,17)$. Myogenic differentiation is accompanied by c-myc downregulation and enforced c-myc expression inhibits the differentiation process $(18,19)$. The myogenic proteins and c-myc can thus be viewed as components of opposing regulatory pathways in which MyoD and its homologues drive the differentiation process and exert an antiproliferative effect (20) whereas c-myc inhibits myogenic differentiation and drives proliferation (21).

The myogenic and myc family member bHLH proteins contain related DNA binding basic domains ( Fig. 1). In particular, MyoD and c-myc are identical at 5 of the 14 amino acids that comprise this motif. Recently, we reported that substitution of the myogenically highly conserved $\mathrm{Leu}_{122}$ in MyoD with the similarly conserved Arg residue present in myc and max family members imparts novel properties to MyoD (22). Although the mutant protein retained the ability to bind to a consensus MyoD site, it was unable to transactivate a promoter containing this site and actually competed with wild-type MyoD in this regard. Furthermore, the mutant MyoD protein gained the capacity to recognize a c-myc/max binding site and, like c-myc, correctly downregulated a gene containing such a site. The acquisition of these unexpected properties by the mutant MyoD protein suggested a novel means by which skeletal muscle tumors (rhabdomyosarcomas) might arise. Point mutation of the highly conserved $\mathrm{Leu}_{122}$ codon (CTG) of MyoD to that encoding an arginine (CGG) found at the analogous position of the c-myc basic domain would result, on the one hand, in a dominant-negative form of the protein that would compete with wild-type myogenic factors and block their transactivation of target genes in myoblasts. On the other hand mutant MyoD could substitute for authentic c-myc protein, which would be downregulated in cells undergoing terminal myogenic commitment. c-myc target genes might therefore continue to be regulated normally resulting in a sustained prolifera- 
tive signal. This combination of inhibited differentiation and enhanced proliferation, mediated either by mutant MyoD protein or other similarly mutant myogenic factors, might initiate or contribute to the neoplastic phenotype. To test this idea, we have surveyed 19 primary rhabdomyosarcoma tumors and 14 rhabdomyosarcoma cell lines for evidence of mutation in the basic domains of any of the four known myogenic proteins. We used PCR to amplify the DNA binding domains of each of the four known myogenic factors and subjected these to singlestrand conformation polymorphism (SSCP) analysis to detect point mutations. SSCP has proven to be a highly sensitive and reliable means of detecting such mutations in a variety of genes (23-25). In our survey we have not detected any differences in the electrophoretic mobility of the fragments obtained from the various tumors or cell lines. These results suggest that the generation of rhabdomyosarcomas is not commonly associated with the acquisition of mutations in the DNA binding domains of any of the known myogenic factors. Other molecular events are more likely to contribute to the sustained proliferative capacity and loss of differentiated phenotype of these highly aggressive childhood tumors.

\section{Methods}

Tumor tissue samples. 19 primary tumors ( 13 embryonal, 6 alveolar) and the following 14 cell lines ( 7 embryonal, 6 alveolar, 1 undifferentiated) were studied: $\mathrm{Rh} 1, \mathrm{Rh} 3, \mathrm{Rh} 4, \mathrm{Rh} 5, \mathrm{Rh} 18, \mathrm{Rh} 30, \mathrm{SA} 2, \mathrm{AD} 2$, Rh28, NIH, A673, A204, TC206C, and MCRB-1 (26-29). Histopathological classification was in accord with the guidelines proposed by Patton and Horn (30). Tumor tissue samples were collected from surgical specimens and snap frozen and stored under liquid nitrogen until further processing. Peripheral leukocytes were obtained from 10 healthy volunteers and separated from other blood components by Ficoll-Hypaque sedimentation. Genomic DNA was isolated from these tissues by standard procedures ( 31 ).

Primers for PCR amplification. The forward primers used to specifically amplify MyoD, myogenin, myf5, and myf6, respectively, and the lengths of the fragments amplified are as follows: Myo D, ${ }^{283}$ CTGTGGGCCTGCAAGGCGTGCAAG ${ }^{306}$ : $167 \mathrm{bp}$; myogenin, GCCGGATCC $^{274}$ TGTAAGAGGAAGTCGGTGTCCGTG ${ }^{291}: 154$ bp; Myf5, GCCGGATCC $^{269}$ AAGAGGAAGTCCACCACCATG ${ }^{288}$ : 157 bp; Myf6, GCCGGATCC $^{309}$ AAGAGAAAATCTGCCCCCACTG ${ }^{330}: 156$ bp.

In the case of myogenin, myf5, and myf6, BamHI sites and "G-C" clamps were added to the forward primers to facilitate cloning. The following reverse PCR primer was chosen for all four myogenic genes that bear identical sequences at this site: 5' GCCAAGCTT CACCTTGGGCAACCGCTGGTTTGG. A HindIII site and "G-C" clamp were added to the reverse primer.

The following primers were used to amplify a 159-bp fragment containing the murine MyoD basic domain from plasmid DNAs: Fwd: ${ }^{441}$ CTGTGGGCCRFCAAGGCGTGCAAG; Rev: CCGAACCAGCGGCTACCCAAGGTG ${ }^{600}$.

PCR amplification and fragment isolation. For plasmid DNA amplification, we chose several MyoD cDNAs in which we had previously introduced specific point mutations in the DNA binding basic domains (22). These were used to establish that the conditions chosen for SSCP analysis could distinguish among these various mutants and the wildtype MyoD cDNA sequence. The specific MyoD plasmid DNAs chosen contained the following mutations: mutant 3: $\mathrm{Ala}_{113} \rightarrow \mathrm{Thr} ; \mathrm{Mu}-$ tant 6: Met $_{116} \rightarrow$ Val; Mutant 7: $\operatorname{Arg}_{117} \rightarrow$ Leu; Mutant 9: Leu $_{122} \rightarrow$ Arg.

For genomic DNA amplification, the PCR mixture contained 500 ng of genomic DNA, $1 \mu \mathrm{g}$ of each primer, $3.75 \mathrm{mM} \mathrm{MgCl}_{2}$ (for myogenin and $\mathrm{MyoD}$ ) or $1.5 \mathrm{mM} \mathrm{MgCl}_{2}$ (for myf5 and myf6), 1:10 reaction volume of magnesium-free 10× PCR buffer (Promega Biotec,
Madison, WI ), $4 \mathrm{mM}$ each of dNTP, $5 \mu \mathrm{Ci}$ of $\alpha-\left[{ }^{32} \mathrm{P}\right] \mathrm{dCTP}$ (sp act, $>3,000 \mathrm{Ci} / \mathrm{mmol}$; Amersham, Arlington, IL), and $0.5 \mathrm{U}$ of Taq polymerase in a $25-\mu \mathrm{l}$ reaction volume. Amplification was performed for 40 cycles with denaturation at $94^{\circ} \mathrm{C}$, annealing at $58^{\circ} \mathrm{C}$, and extension at $72^{\circ} \mathrm{C}$ for $1 \mathrm{~min}$ each. Similar conditions were used to amplify MyoD cDNA sequences except that the PCRs contained $100 \mathrm{pg}$ of the appropriate linearized plasmid DNA. Specific bands were excised from a 5\% acrylamide gel, incubated in an elution buffer containing $0.5 \mathrm{M}$ ammonium acetate, $0.01 \mathrm{M}$ magnesium acetate, $1 \mathrm{mM}$ EDTA, and $0.1 \%$ SDS overnight, extracted with phenol/chloroform/isoamyl alcohol, precipitated with ethanol, and resuspended in $20 \mu \mathrm{l}$ of distilled water. The eluted fragments migrated as single bands upon reelectrophoresis in nondenaturing polyacrylamide or agarose gels (not shown). That the PCR product obtained derived from the appropriate gene was confirmed by restriction mapping and, in select cases, DNA sequencing (not shown).

SSCP analysis. SSCP analysis was performed essentially as described (23). Approximately $10,000 \mathrm{cpm}$ of the purified PCR fragment $(1 \mu \mathrm{l}$ ) was mixed with $9 \mu \mathrm{l}$ of a loading dye ( $20 \mathrm{mM}$ EDTA, $0.1 \%$ SDS, $95 \%$ formamide, $0.04 \%$ xylene cyanol, $0.04 \%$ bromophenol blue), boiled for $5 \mathrm{~min}$, and quick chilled on ice. $2.5 \mu \mathrm{l}$ was loaded on a $5 \%$ acrylamide gel containing $6.25 \%$ glycerol and electropheresis was carried out at $4{ }^{\circ} \mathrm{C}$ for $4 \mathrm{~h}$ at $35 \mathrm{~mA}$. The gels were dried under vacuum and exposed to $\mathrm{x}$-ray film for $16 \mathrm{~h}$ at $-80^{\circ} \mathrm{C}$ in the presence of an intensifying screen.

\section{Results and Discussion}

To first establish that the conditions chosen for SSCP analysis could distinguish a mutant gene from the wild type, we used several plasmids that encoded either a wild-type murine MyoD cDNA or the same cDNA with individual point mutations deliberately engineered into the DNA binding basic domain (22) (Fig. 2). In all cases tested, DNA fragments containing point mutations were readily distinguishable from the wild-type sequence and from one another after SSCP analysis. We conclude from these experiments that SSCP analysis provides a sensitive and reliable means of detecting point mutation in the MyoD basic domain.

We next analyzed genomic DNA samples obtained from 33 rhabdomyosarcomas (19 primary tumors and 14 cell lines) and from the peripheral leukocytes of 10 normal individuals.

\begin{tabular}{|c|c|c|c|c|c|c|c|c|c|c|c|c|c|c|}
\hline \multirow[b]{2}{*}{ Myogenin: } & \multirow[b]{2}{*}{$\Omega$} & \multirow[b]{2}{*}{$\mathbf{R}$} & \multirow[b]{2}{*}{$\mathbf{R}$} & \multirow[b]{2}{*}{$\mathbf{R}$} & \multirow[b]{2}{*}{ A } & \multirow[b]{2}{*}{ A } & \multirow[b]{2}{*}{$T$} & \multirow[b]{2}{*}{$\mathbf{L}$} & \multirow[b]{2}{*}{ R } & \multirow[b]{2}{*}{$\mathbf{E}$} & \multirow[b]{2}{*}{ K } & \multirow[b]{2}{*}{$\mathbf{R}$} & \multirow[b]{2}{*}{$\mathbf{R}$} & $\star$ \\
\hline & & & & & & & & & & & & & & L \\
\hline Myf 5: & D & $\mathbf{R}$ & $\mathbf{R}$ & K & A & A & $T$ & M & R & E & R & R & R & L \\
\hline Myf 6: & D & $\mathbf{R}$ & $\mathbf{R}$ & $\mathbf{K}$ & A & A & $\mathbf{T}$ & $\mathbf{L}$ & R & $\mathbf{E}$ & $\mathbf{R}$ & $\mathbf{R}$ & $\mathbf{R}$ & $\mathbf{L}$ \\
\hline Myo D: & D & $\underset{i}{R}$ & $\mathbf{R}$ & $\mathbf{K}$ & $\begin{array}{c}\mathbf{A}_{3} \\
\end{array}$ & $\begin{array}{l}\text { A } \\
4\end{array}$ & $\mathbf{T}$ & M & $\begin{array}{l}R \\
8\end{array}$ & E & $\mathbf{R}$ & $\mathbf{R}$ & R & L \\
\hline C-myc: & v & $K$ & $\mathbf{R}$ & $\mathbf{R}$ & $\mathbf{T}$ & H & $\mathbf{N}$ & v & $L$ & E & $\mathbf{R}$ & $\mathbf{Q}$ & $\mathbf{R}$ & $\mathbf{R}$ \\
\hline N-myc: & $\mathbf{E}$ & $\mathbf{R}$ & $\mathbf{R}$ & $\mathbf{R}$ & $\mathbf{N}$ & H & $\mathbf{N}$ & 1 & $\mathbf{L}$ & $\mathbf{E}$ & $\mathbf{R}$ & $\mathbf{Q}$ & $\mathbf{R}$ & $\mathbf{R}$ \\
\hline L-myc: & $\mathbf{T}$ & $K$ & $\mathbf{R}$ & K & $\mathbf{N}$ & H & $\mathbf{N}$ & $\mathbf{F}$ & L & $\mathbf{E}$ & $\mathbf{R}$ & $K$ & $\mathbf{R}$ & $\mathbf{R}$ \\
\hline Max: & D & $\mathbf{K}$ & $\mathbf{R}$ & A & H & H & $\mathbf{N}$ & A & $\mathbf{L}$ & $\mathbf{E}$ & $\mathbf{R}$ & $\mathbf{K}$ & $\mathbf{R}$ & $\mathbf{R}$ \\
\hline
\end{tabular}

Figure 1. Amino acid (aa) sequence comparison of the basic domain. The sequences compared are the following: myogenin (aa 81-94), MyoD (aa 109-122), myf5 (aa 83-96), myf6 (aa 93-106). The amino acid residues in the basic region that were changed to those found in the analogous position in c-myc are numbered from 1 through 9. Mutant 9 where $\mathrm{Leu}_{122}$ was changed to Arg is indicated by an astrix. 


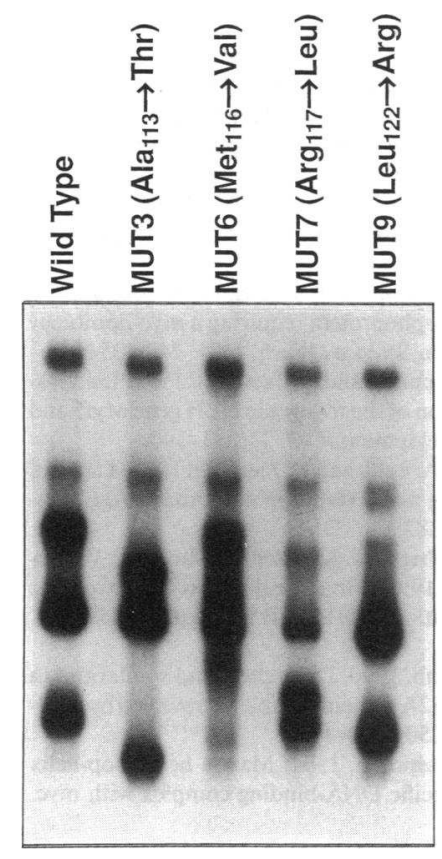

Figure 2. Mobility shift analysis of murine MyoD mutants. DNA fragments encoding the basic domain of MyoD from wild-type and mutants $3,6,7$, and 9 (22) were analyzed for SSCP as described in Methods. Each mutant fragment migrated with a characteristic pattern different from that of the wild type.

PCR was performed using primers specific for MyoD, myogenein, myf5, and myf6. Specific amplified bands were obtained in all cases and were subsequently purified by polyacrylamide gel electrophoresis before being subjected to SSCP analysis. The myogenic gene of origin of the amplified fragment was confirmed by establishing the presence of predicted restriction endonuclease sites or by DNA sequencing of selected cloned fragments (not shown). Under our experimental conditions, the patterns of DNA strand migration were identical for fragments obtained from either normal or tumor DNAs, suggesting identical DNA sequences in the basic domains (Fig. 3). In the case of myogenin this was confirmed by cloning and sequencing several of the PCR-amplified DNA fragments obtained from tumor DNAs. In all cases, the DNA sequences of the basic domains corresponded to the previously published sequence (32-34). In particular, we found no evidence of mutation at the highly conserved Leu that corresponds to $\mathrm{Leu}_{122}$ of MyoD. Thus, we can conclude from this study that mutation within the DNA binding domain of none of the four myogenic factors discussed here is commonly associated with the occurrence of rhabdomyosarcomas.

We and others have provided evidence that $\operatorname{Arg}_{367}$ of $\mathrm{c}-\mathrm{myc}$ is a critical determinant of inner dinucleotide (CG) binding specificity in the c-myc E-box recognition site, CACGTG (35, 36 ). This amino acid, highly conserved among myc/max family members, corresponds to the equally well-conserved leucine residue of the four myogenic factors $\left(\mathrm{Leu}_{122}\right.$ in $\left.\mathrm{MyoD}\right)$, which, by analogy, would be important in the recognition of the CC inner dinucleotide sequence in the $\mathrm{MyoD}$ binding site (CACCTG) by the MyoD-E12/E47 heterodimer. Given the importance of these basic domain residues to DNA binding and, in particular, to the profound functional consequences of mutation at these sites (35), how might we explain why they are not mutated in rhabdomyosarcomas? Perhaps the simplest explanation lies in the redundancy of the myogenic pathway. Assuming that a mutation such as the $\mathrm{MyoD} \mathrm{Leu}_{122} \rightarrow$ Arg did occur, it is quite conceivable that its effects would be negligible due to its competition for binding sites, not only with wild-type MyoD encoded by the unmutated allele but with the other myogenic factors as well. Similarly, despite the progressive decline of c-myc protein levels in differentiating cells, c-myc binding sites might continue to be occupied by max homodimers that bind with quite high affinity to these sites $(37,38)$. Other bHLH proteins, such as the upstream stimulatory factor (39), and other more recently described max dimerization partners, such as mad and mxi $(40,41)$, would also be expected to compete with mutant MyoD proteins for these sites as well. Under such conditions basic region mutations of any individual myogenic protein might not be subject to the selective pressures necessary for the genesis of a rhabdomyosarcoma. Thus, one additional beneficial consequence of bHLH family redundancy might be to guard against the full consequences of such deleterious mutations.
A
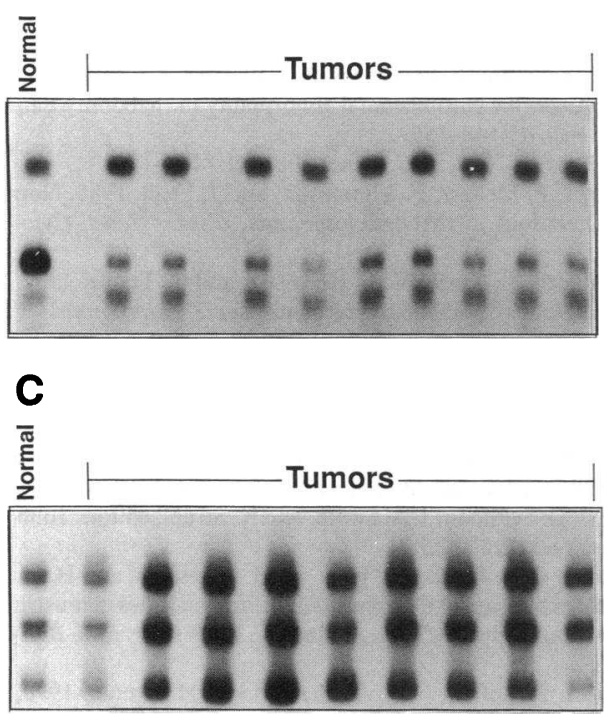

B

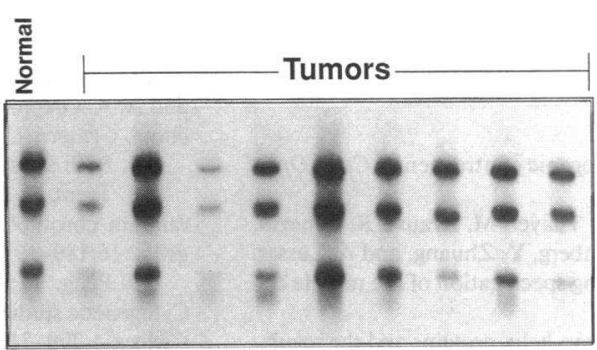

D

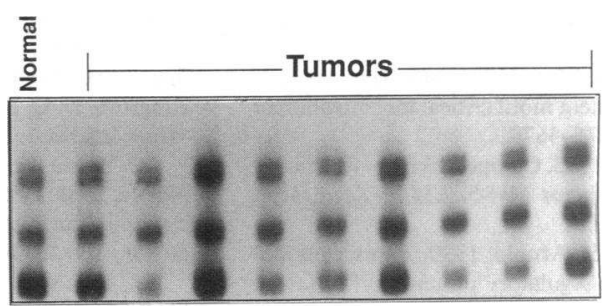

Figure 3. Representative SSCP analysis of myogenin, MyoD, myf5, and myf6 DNA fragments. Genomic DNA from either normal or tumor tissue were amplified by PCR with primers specific for each of the myogenic genes and subjected to SSCP analysis as described in Methods. The various panels represent samples amplified with primers specific for the following order of genes: $(A)$ myogenin, $(B)$ MyoD, $(C)$ myf5, and $(D)$ myf6. There appears to be no difference in the migratory pattern between the normal and tumor DNA for all the genes analyzed. 
At least two additional factors might conspire against the selection of "activating" mutations within the basic regions of myogenic genes. One of these is the apparent absence in rhabdomyosarcomas of one or more accessory molecules necessary for the function of the MyoD transactivation domain (42). The lack of a myogenically conducive environment might explain why neither endogenous myogenic proteins, commonly expressed in rhabdomyosarcomas, nor those driven by transfected expression vectors, significantly alter the transformed phenotype of such tumors (43). The second factor that might select against the generation of activating mutations is the nature of the transactivating domains of the myogenic proteins themselves. Although the MyoD Leu ${ }_{122} \rightarrow$ Arg mutation does indeed mimic c-myc in terms of its ability to regulate a c-mycresponsive gene, this effect is unlikely to be universal. Other accessory proteins that interact specifically with the c-myc transactivation domain may be essential for the proper regulation of target genes involved in the transformation pathway. Mutant myogenic proteins with the capacity to bind c-myc sites might not necessarily interact with the accessory factors required for subsequent transcriptional control of all c-myc regulated genes. Consistent with this notion is the inability of the mutant MyoD protein to transform susceptible rat embryo cells in conjunction with an activated ras oncogene (our unpublished observations).

In summary, we have demonstrated that mutations in the DNA binding domains of four myogenic proteins do not occur with any appreciable frequency in rhabdomyosarcomas. Such mutations may be selected against as a result of the redundancy of the myogenic and c-myc pathways, an intracellular environment that prevents the proper function of the transcriptional activation domains of the myogenic proteins, or lack of binding of accessory proteins necessary for the proper regulation of c-myc-responsive genes.

\section{Acknowledgments}

We thank John Law for providing the tumor DNA samples and Selma Siegel for helpful discussions.

This work was supported by National Institutes of Health grant HL-33741 to E. V. Prochownik, and NIH grant CA-23099, Institutional Cancer Center CORE grant CA-21765, and American Lebanese Syrian Associated Charities to D. N. Shapiro.

\section{References}

1. Emerson, C. P. 1990. Myogenin and myogenic control genes. Curr. Opin. Cell Biol. 2:1065-1075.

2. Weintraub, H., R. Davis, S. Tapscott, M. Thayer, M. Krause, R. Benezra, T. K. Blackwell, D. Turner, R. Rupp, S. Hollenberg, Y. Zhuang, and A. Lassar. 1991. The myoD gene family: nodal point during specification of the muscle cell lineage. Science (Wash. DC). 251:761-766.

3. Wright, W. E. 1992. Muscle basic helix-loop-helix proteins and the regulation of myogenesis. Curr. Opin. Genetic Development. 2:243-248.

4. Davis, R. L., P. F. Cheng, A. B. Lassar, and H. Weintraub. 1990. The myoD DNA binding domain contains a recognition code for muscle-specific gene activation. Cell 60:733-746.

5. Brennan, T. J., T. Chakraborty, and E. N. Olson. 1991. Mutagenesis of the myogenin basic region identifies an ancient protein motif critical for activation of myogenesis. Proc. Natl. Acad. Sci. USA. 88:5675-5679.

6. Winter, B., T. Braun, and H. H. Arnold. 1992. Co-operativity of functional domains in the muscle-specific transcription factor Myf-5. EMBO (Eur. Mol. Biol. Organ.) J. 11:1843-1855.

7. Braun, T., B. Winter, E. Bober, and H. H. Arnold. 1990. Transcriptional activation domain of the muscle-specific gene-regulatory protein myf5. Nature (Lond.). 346:663-665.
8. Sassoon, D., G. Lyons, W. E. Wright, V. Lin, A. Lassar, H. Weintraub, and M. Buckingham. 1989. Expression of two myogenic regulatory factors myogenin and MyoD1 during mouse embryogenesis. Nature (Lond.). 341:303-307.

9. Bober, E., G. E. Lyons, T. Braun, G. Cossu, M. Buckingham, and H. H. Arnold. 1991. The muscle regulatory gene, Myf-6, has a biphasic pattern of expression during early mouse development. J. Cell Biol. 113:1255-1265.

10. Yutzey, K. E., S. J. Rhodes, and S. F. Konieczny. 1990. Differential trans activation associated with the muscle regulatory factors MyoD1, myogenin and MRF4. Mol. Cell. Biol. 10:3934-3944.

11. Tapscott, S. J., R. L. Davis, M. J. Thayer, P. F. Cheng, H. Weintraub, and A. B. Lassar. 1988. MyoD: a nuclear phosphoprotein requiring a myc-homology region to convert fibroblasts to myoblasts. Science (Wash. DC). 242:405-411.

12. Rudnicki, M. A., T. Braun, S. Hinuma, and R. Jaenisch. 1992. Inactivation of MyoD in mice lead to up-regulation of the myogenic HLH gene Myf5 and results in apparently normal muscle development. Cell. 71:383-390.

13. Braun, T., M. A. Rudnicki, H. H. Arnold, and R. Jaenisch. 1992. Targeted inactivation of the muscle regulatory gene myf-5 results in abnormal rib development and perinatal death. Cell. 71:369-382.

14. Lassar, A. B., R. L. Davis, W. E. Wright, T. Kadesch, C. Murre, A. Voronova, D. Baltimore, and H. Weintraub. 1991. Functional activity of myogenic HLH proteins require hetero-oligomerization with E12/E47-like protein in vivo. Cell. 66:305-315.

15. Blackwell, T. K., and H. Weintraub. 1990. Differences and similarities in DNA-binding preferences of MyoD and E2A protein complexes revealed by binding site selection. Science (Wash. DC). 250:1104-1110.

16. Blackwood, E. M., and R. N. Eisenman. 1991. Max: a helix-loop-helix zipper protein that forms a sequence-specific DNA-binding complex with myc. Science (Wash. DC). 251:1211-1217.

17. Prendergast, G. C., D. Lawe, and E. B. Ziff. 1991. Association of Myn, the murine homolog of max, with c-myc stimulates methylation-sensitive DNA binding and ras cotransformation. Cell. 65:395-407.

18. Falcone, G., F. Tato, and S. Alema. 1985. Distinctive effects of the viral oncogenes $m y c, e r b, f p s$ and $s r c$ on the differentiation program of quail myogenic cells. Proc. Natl. Acad. Sci. USA. 82:426-430.

19. Schneider, M. D., M. B. Perryman, P. A. Payne, G. Spizz, R. Roberts, and E. N. Olson. 1987. Autonomous expression of c-myc in $\mathrm{BC}_{3} \mathrm{Hl}$ cells partially inhibits but does not prevent myogenic differentiation. Mol. Cell. Biol. 7:19731977.

20. Sorrentino, V., R. Pepperkok, R. L. Davis, W. Ansorge, and L. Philipson. 1990. Cell proliferation inhibited by MyoD1 independently of myogenic differentiation. Nature (Lond.). 345:813-815.

21. Miner, J. H., and B. L. Wold. 1991. C-myc inhibition of MyoD and myogenin-initiated myogenic differentiation. Mol. Cell. Biol. 11:2842-2851.

22. Van Antwerp, M. E., D. G. Chen, C. Chang, and E. V. Prochownik. 1992 A point mutation in the MyoD basic domain imparts c-Myc like properties. Proc. Natl. Acad. Sci. USA. 89:9010-9014.

23. Orita, M., A. H. Iwahana, H. Kanazawa, K. Hayashi, and T. Sekiya. 1989 Detection of polymorphisms of human DNA by gel electrophoresis as singlestrand conformation polymorphisms. Proc. Natl. Acad. Sci. USA. 86:2766-2770.

24. Labrune, P., D. Melle, F. Rey, M. Berthelon, C. Caillaud, R. Rey, A Munnich, and S. Lyonnet. 1991. Single-strand conformation polymorphism for detection of mutation and base substitutions in phenylketonuria. Am. J. Hum. Genet. 48:1115-1120.

25. Ptacek, L. J., A. L. George, Jr., R. C. Griggs, R. Tawii, R. G. Kallen, R. L. Barchi, M. Robertson, and M. F. Leppert. 1991. Identification of a mutation in the gene causing hyperkalemic periodic paralysis. Cell. 67:1021-1027.

26. Douglas, E. C., M. Valentine, E. Etcubanas, B. L. Webber, P. J. Houghton, and A. A. Green. 1987. A specific chromosomal abnormality in rhabdomyosarcoma. Cytogenet. Cell Genet. 45:148-155.

27. Both are ATCC lines. 1973. J. Natl. Cancer Inst. 51:1417-1423.

28. Trent, J., J. Casper, P. Meltzer, F. Thompson, and J. Fogh. 1985. Non random chromosome alterations in rhabdomyosarcoma. Cancer Genet. Cytogenet. 16:189-197.

29. Peng, W., T. Knutsen, K. Thell, M. E. Horowitz, and T. Triche. 1992. Cytogenetic studies in subgroups of rhabdomyosarcoma. Genes Chromosomes \& Cancer. 5:299-310.

30. Patton, R. B., and R. C. Horn, Jr. 1963. Rhabdomyosarcoma: clinical and pathological features and comparison with human fetal and exbryonal skeletal muscle. Surgery (St. Louis). 52:572.

31. Strauss, W. M. 1990. Preparation of genomic DNA from mammalian tissue. In Current Protocols in Molecular Biology. F. M. Ausubel, R. Brent, R. E. Kingston, D. D. Moore, J. G. Seidman, J. A. Smith, and K. Struhl, editors. John Wiley \& Sons, Inc., New York. 2.2.1-2.2.2.

32. Braun, T., E. Bober, G. B. Denker, S. Kotz, K. H. Grzeschik, and H. H. Arnold. 1989. Differential expression of myogenic determination genes in muscle cells: possible auto activation by the myf gene products. EMBO (Eur. Mol. Biol. Organ.) J. 8:3617-3625.

33. Braun T., E. Bober, B. Winter, N. Rosenthal, and H. H. Arnold. 1990 Myf6, a new member of the human gene family of myogenic determination 
factors: evidence for a gene cluster on chromosome 12. EMBO (Eur. Mol. Biol. Organ.) J. 9:821-831.

34. Braun, T., G. B. Denker, E. Bober, E. Tannich, and H. H. Arnold, H. H. 1989. A novel human muscle factor related to but distinct from MyoDl induces myogenic conversion in 10T1/2 fibroblasts. EMBO (Eur. Mol. Biol. Organ.) J. 8:701-709.

35. Prochownik, E. V., and M. A. VanAntwerp. 1993. Differential patterns of DNA binding by myc and max proteins. Proc. Natl. Acad. Sci. USA. 90:960-964.

36. Dang, C. V., C. Dolde, M. L. Gillison, and G. J. Kato. 1992. Discrimination between related DNA sites by a single amino acid residue of myc-related basic-helix-loop-helix proteins. Proc. Natl. Acad. Sci. USA. 89:599-602.

37. Kretzner, L., E. M. Blackwood, and R. N. Eisenman. 1992. Myc and max proteins possess distinct transcriptional activities. Nature (Lond.). 359:426-429.

38. Littlewood, T. D., B. Amati, H. Land, and G. I. Evan. 1992. Max and c-myc/max DNA-binding activities in cell extracts. Oncogene. 7:1783-1792.
39. Gregor, P. D., M. Sawadago, and R. G. Roeder. 1990. The adenovirus major late transcription factor USF is a member of the helix-loop-helix group of regulatory proteins and binds to DNA as a dimer. Genes \& Dev. 4:1730-1740.

40. Ayer, D. E., L. Kretzner, and R. N. Eisenman. 1993. Mad: A heterodimeric partner for Max that antagonizes myc transcriptional activity. Cell. 72:211-222.

41. Zervos, A. S., J. Gyuris, and R. Brent. 1993. Mxil, a protein that specifically interacts with max to bind myc-max recognition sites. Cell. 72:223-232.

42. Tapscott, S. J., M. J. Thayer, and H. Weintraub. 1993. Deficiency in rhabdomyosarcomas of a factor required for $\mathrm{MyoD}$ activity and myogenesis. Science (Wash. DC). 259:1450-1453.

43. Hiti, A. L., E. Bogenmann, F. Gonzales, and P. A. Jones. 1989. Expression of the MyoDl muscle determination gene defines differentiation capability but not tumorigenicity of human rhabdomyosarcomas. Mol. Cell. Biol. 57:47224730. 